\title{
The effect of damage location on the performance of seismically damaged concrete filled steel tube columns at fire
}

\author{
E. Talebi ${ }^{\mathrm{a} *}$, M. Korzen ${ }^{\mathrm{a}}$, A. Espinós ${ }^{\mathrm{b}}$, and S. Hothan ${ }^{\mathrm{a}}$ \\ ${ }^{a}$ Division Fire Engineering, Bundesanstalt für Materialforschung und - prüfung (BAM), Germany \\ ${ }^{b}$ ICITECH, Universitat Politècnica de València, Spain \\ *corresponding author, e-mail address: elnaz.talebi@bam.de
}

\begin{abstract}
In this paper, a nonlinear three-dimensional finite element (FE) model was developed and validated to study the effect of seismic damage location on the response of concrete filled tube (CFT) columns at fire after earthquakes. Three analyses were conducted consecutively in the modelling, namely, cyclic, thermal and structural. Results of the cyclic loading analysis comprising residual deformations were applied as the initial condition to the thermal-stress model, replicating the seismic performance of column. Following, a nonlinear sequentially coupled-thermal stress analysis was carried out to investigate the fire response of CFT columns after the seismic event. Three damage scenarios were contemplated, considering any possible potential damages that could be generated by the earthquake loading on CFT columns. The accuracy of the proposed FE model was examined by comparing the numerical results with that of available tests on fire and cyclic loading. By means of the validated model, the performance of damaged CFT columns was then investigated under fire after earthquakes. The level of damage was assumed as a high damage level, presuming that the column reached $50 \%$ of its lateral resistance while still maintaining its overall stability after the earthquake. The results were presented broadly, including the axial deformation history as well as the fire resistance time for CFT columns. To have a comprehensive insight on the influence of damage location in columns, the fire response of damaged specimens was compared with that of an intact one.
\end{abstract}

Keywords: Fire after earthquake; Concrete filled tube (CFT) column; Finite element model; Seismically damaged column; Damage location; Fire performance.

\section{Introduction}

Concrete filled tube (CFT) columns are used increasingly in many structural applications for exhibiting high performance against severe events. Many studies dedicated on representing their high seismic resistance [1-3], while their superior fire response is reported separately by others [4-7]. CFT columns gain their high fire resistance via two main effects, namely, the shield effect of the steel tube and the heat sink effect of the concrete. The former protects the in-filled concrete from heating directly and maintains its integrity, besides, the later postpones temperature increase in the concrete core. Up to now, several studies dedicated on the numerical simulation of CFT columns at fire [8-11] and earthquake [12-14] but none of them considers the behavior of these composite columns under the combination of both incidents as a multi-hazard event.

Ding and Wang [8] developed an advanced model for predicting the fire performance of CFT columns with circular and square crosssections. They showed that the existence of slip at the steel-concrete interface as well as the tensile strength of concrete material has minor effect on the fire resistance of CFT columns. Espinos et al., [9] studied numerically the behavior of axially loaded CFT columns with circular cross-sections at fire. They showed that adopting the constant value of $h_{j}=200 \mathrm{~W} / \mathrm{m}^{2}$ for the thermal conductance at the gap existed in the steel tube-concrete interface leads to the accurate results. In addition, they confirmed 
that the value of $L / 1000$ that has been used widely by other researchers is an acceptable quantity for modelling the initial imperfection.

$\mathrm{Hu}$ et al., [12] evaluated the response of CFT columns under the combination of axial compressive force and bending moment. Their study showed that the larger the imposed axial force, the bigger the confining effect provided by the steel tube on the concrete core. Chang et al., [14] studied the performance of an enhanced type of CFT column, as the steel reinforced-concrete filled-steel tubular column (SRCFST) under cyclic loading. Their study revealed that the insertion of a steel section within the concrete core could noticeably enhance both the strength and the stiffness of conventional circular CFT columns. This resulted because the steel section could carry a portion of applied lateral loading, which led to a decrease in the tensile zone of in-filled concrete.

A review of historical records prove that the damages generated by post-earthquake fires can be very substantial, often exceeding the damage produced by solo earthquake [15-16]. Hence, the occurrence of fire ensuing earthquakes is a noteworthy concern to be considered on the resistance of structural members, especially for those are located in the moderate-to-high seismically zones. Although several researchers investigated the resistance of CFT columns under fire and earthquake, there is still a lack of understanding on the response of these composite columns under the fire after earthquake as a multi-hazard incident. Apparently, by the occurrence of an earthquake, the structural columns would be subjected to the local damages, depending on the severity of the seismic event as well as the strength of the section. Following, the location of the corresponding pre-existed damages would influence the response of columns against the ensuing fire. With regards to the lack of numerical studies in this area, this work was aimed to investigate numerically the effect of seismic damage location on the fire resistance of CFT columns.

In this study, a three-dimensional nonlinear finite element (FE) model was developed, using ABAQUS program [17]. Three analysis steps were considered consecutively in the modeling, namely, cyclic, thermal and structural analyses. The effect of earthquake loading on the column was simulated via cyclic loading of the specimen. The outcome of seismic analysis including the residual deformations were applied stress-free as the initial condition to the next analysis step, i.e., sequentially thermal-stress analysis. The accuracy of numerical model developed in this paper was validated by comparing the FE results with the experimental tests available in the literature on the cyclic testing [3] and fire testing of CFT columns [4]. By means of validated model on the cyclic response and fire resistance of CFT columns separately, the performance of these composite columns were then explored under the combination of both events.

\section{Numerical model under cyclic loading}

A three-dimensional nonlinear FE model was conducted in ABAQUS package [17] to simulate the effect of earthquake loading on composite tubular columns. Eight CFT circular columns were tested by Han and Yang [3] and among them, the specimen labeled as SC2-3 was chosen for the verification of cyclic analysis in this study. To accurately replicate the test predictions in the FE simulation, the materials, loading and boundary conditions were modelled exactly the same as those used in the reference test [3].

The steel tube, in-filled concrete and the steel stub were meshed using three-dimensional eight node solid elements with reduced integration (C3D8R) available in ABAQUS [17]. To efficiently capture the occurrence of local buckling, mesh refinement was done in the areas that the local buckling of steel tube was anticipated. Result of a mesh sensivity study proved that the mesh size of $20 \mathrm{~mm}$ and $10 \mathrm{~mm}$ in the course and finer regions led to good results with reasonable computational time. Two rigid steel plates with the thickness of $16 \mathrm{~mm}$ were modelled at the column endings, through which the axial load and the boundary conditions were appended. A rigid steel stub with a length of $150 \mathrm{~mm}$ was modelled at the mid-span of the column, through which the cyclic loading was applied. The pined-pined boundary conditions were modelled at both endings while one end was allowed to move in the longitudinal direction, as was in the test. The loading was applied in consecutive steps as follows. First, the axial load was applied to the top plate and kept constant through the whole analysis, simulating 
the reaction from the upper stories. This load was equal to $40 \%$ of the ultimate axial strength of the column. The lateral cyclic load was then applied to the steel stub according to the ATC24 [18] guidelines to simulate the seismic load. The detailed description on the modelling technique, the parameters used as well as the material simulation at room temperature can be found elsewhere [19].

\subsection{Validation of numerical results under cyclic loading}

The accuracy of numerical simulation on the response of CFT columns against cyclic loading was verified with a series of experimental observations recorded by Han et al., [3]. The final state of the deformed column against cyclic loading is presented in Fig. 1.

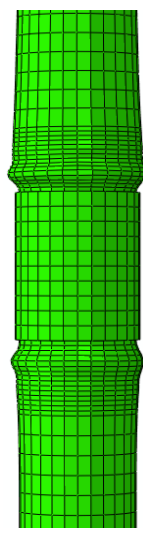

(a)

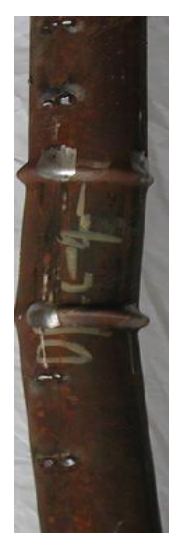

(b)
Fig. 1. Final deformed shape of the modelled CFT column under lateral cyclic loading in the (a) FE model, and (b) test [3]

The hysteresis response of the modelled column in terms of the lateral load versus midspan displacement is shown in Fig. 2.

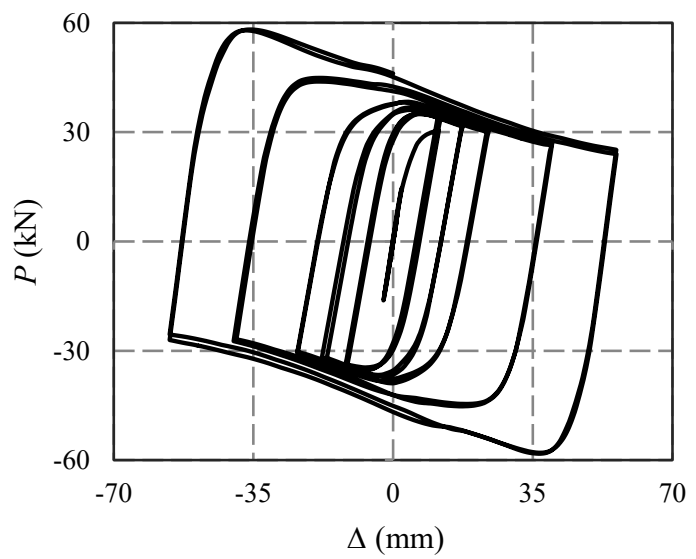

(a)

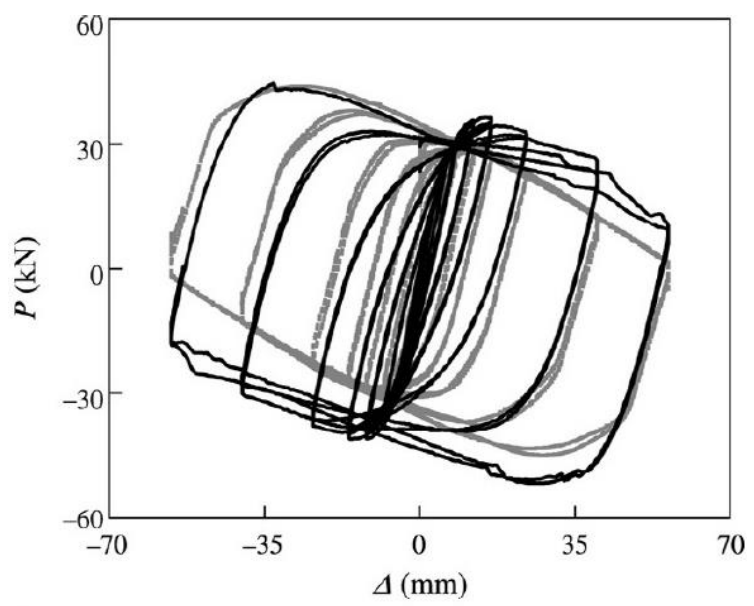

(b)

Fig. 2. Mid-span lateral deflection versus lateral load of column SC2-3 in the (a) FE model, (b) test [3]

In general, it can be seen that there is a good agreement between the FE results and those predicted in the reference test [3].

\section{Numerical model under fire loading}

To simulate the response of CFT columns under fire condition, a three-dimensional numerical simulation was conducted, using ABAQUS program [17]. The accuracy of this part of simulation was examined by comparing the FE results with the observations of the fire tests on circular CFT columns conducted by Lie and Chabot [4]. Thirty-eight CFT circular columns were tested by Lie and Chabot [4] and among them a sample labeled as C-11 was chosen for the validation purpose in this study.

Due to the existence of symmetry both in the length and the cross-section of the column, only one-quarter of the sample was modelled. The boundary conditions applied to the end plates were fixed-fixed at both ends, while one end was allowed to move in the longitudinal direction as was in the test [4]. The fire was imposed for 80 minutes to the $3048 \mathrm{~mm}$ central length of columns, following the test situation. The detailed information on the analysis procedure and the material modelling at elevated temperature is explained thoroughly elsewhere [19].

\subsection{Validation of numerical results under fire loading}

The accuracy of proposed numerical thermal-stress model was examined by comparing the FE results with a series of fire 
tests conducted on circular CFT columns at the National Research Council of Canada [4]. The heat transfer analysis results in terms of temperature-time history at some selected points within the composite columns are presented in Fig. 3.

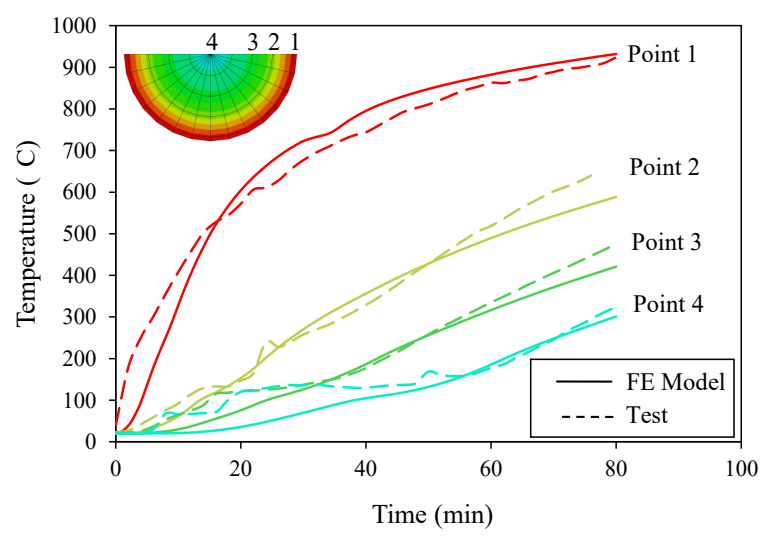

Fig. 3. Temperature distribution within the cross-section of modelled column

The final deformed state of the modelled CFT column against constant axial load and fire loading is shown in Fig. 4.

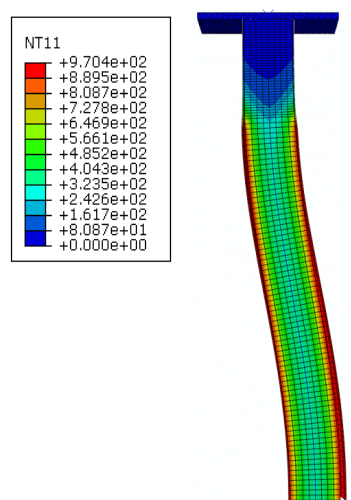

(a)

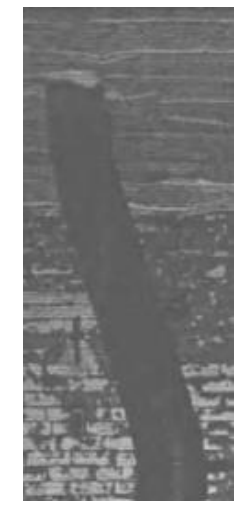

(b)
Fig. 4. The final deformed shape of modelled column after heating at fire in the (a) FE model and (b) Test [4] (color counter shows the temperature distribution within the column's cross-section)

Figure 5 shows the extension or contraction of modelled column due to fire loading in terms of the axial displacement history of column's end plate. The agreements between the results show that the proposed thermal-stress model could sufficiently simulate the fire response of CFT column.

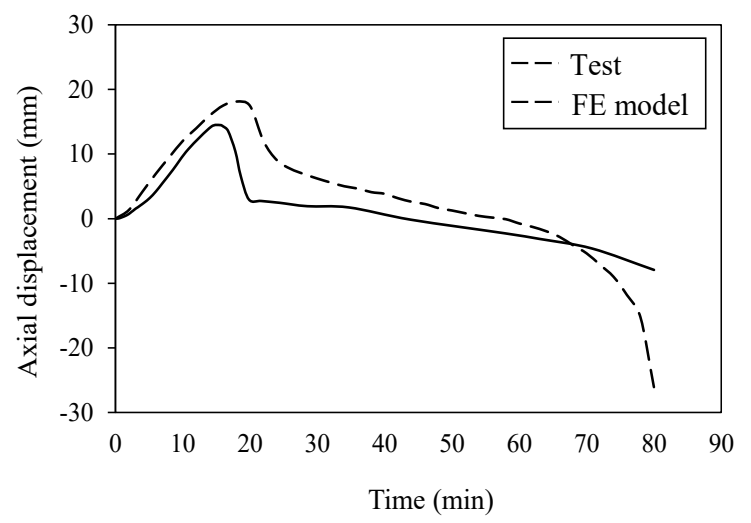

Fig. 5. Axial displacement versus time for column C-11under fire loading

\section{Numerical model under the post- earthquake fire loading}

For predicting the response of CFT columns under fires after earthquakes numerically, two successively analysis steps are required, namely cyclic and sequentially thermal-stress analysis. Benefiting the validated model under both cyclic and fire loading described in previous sections, the post-earthquake fire response of CFT columns can now be simulated by combining two analysis procedures. To have a comprehensive study on the fire resistance of CFT columns after earthquake, the result of this section was compared with that of an intact (undamaged) similar column. In this section, label C-1D denotes the column, which was damaged due to cyclic loading and $\mathrm{C}-1$ refers to the intact one. Provided below, there is a brief description on the post-earthquake fire simulation of CFT columns.

\subsection{Analysis procedure}

For simulating the behavior of CFT columns under fire ensuing the seismic event, the analysis was conducted serially as follows. First, the static analysis was conducted under the cyclic loading for simulating the performance of column at earthquake. The damage level caused by the cyclic loading was assumed as high level, with the hypothesis that the column reached $50 \%$ of its lateral resistance during earthquake, meanwhile, it was still capable of sustaining the applied loads. Hence, an initial analysis was conducted to calculate the lateral resistance of the CFT column. Subsequently, the column was subjected to the constant axial load and lateral displacement cycles up to the $50 \%$ of the column's lateral resistance, simulating the presumed seismic 
damage level. For this, the cyclic loading analysis was terminated intentionally after the column gained $50 \%$ of its lateral resistance, monitoring the lateral load-displacement curve during the analysis. Note that the value of $50 \%$ is just a presumed level in this case study with the assumption that the steel tube would not experience any fracture up to this strength limit.

Next, the coupled thermal-stress analysis was conducted for simulating the fire event. In this step, the residual deformations resulted from the lateral loading analysis was defined as the initial condition to the model. To avoid any complexity in the modelling, the plastic deformations were transferred as 'stress-free' from the cyclic to the thermal-stress model.

\subsection{Loading and mesh model}

The constant axial load was considered as $30 \%$ of the axial strength of the column, which was computed per EN 1994-1-1[20]. Two steel rigid plates were modelled at the column endings, through which the loading and boundary conditions were appended. The column was modelled as fixed at the bottom while free to rotate at the top ending, forming a fixed-pinned ending condition. The cyclic loading was conducted based on ATC-24 guideline [18] and applied to the top end plate. The loading history comprised of elastic and inelastic cycles. The elastic cycles were applied under the load control mode at the load levels of $0.25 P_{u}, 0.5 P_{u}$ and $0.7 P_{u}$, where $P_{u}$ is the lateral load capacity of the section, which was calculated per EN 1994-1-1 [20].

The inelastic cycles were then applied at the displacement levels of $\Delta_{y}, 1.5 \Delta_{y}, 2 \Delta_{y}, 3 \Delta_{y}$, etc., where, $\Delta_{y}$ is the lateral yield displacement of the column. Based on ATC-24 [18], two cycles were imposed at the elastic levels, following three cycles at each displacement levels of $\Delta_{y}$, $1.5 \Delta_{y}$ and $2 \Delta_{y}$, and two cycles at each further displacement levels.

Since the lateral loading was applied to the top ending plate, the mesh refinement was conducted in the vicinity of column bottom ending to better capture the local buckling of the tube. The mesh size was selected as $20 \mathrm{~mm}$ and $10 \mathrm{~mm}$ for the coarser and finer areas, respectively. The steel tube and in-filled concrete were meshed using eight node solid elements in ABAQUS [17]. In the thermalstress model, first the column was subjected to heating per ISO-834 [21] fire curve for the presumed time of 90 minutes. Next, the static analysis was conducted at load-control mode, considering the nodal displacements and temperatures obtained from the cyclic and thermal analysis, respectively.

\section{Results and discussion}

\subsection{Bottom seismic damage scenario}

Figure 6 shows the final state of column C-1D after subjected to the cyclic loading and the ensuing fire. Owing to the maximum moment generated by the lateral loading cycles close to the column bottom ending, the local buckling of the steel tube was exhibited at this region.

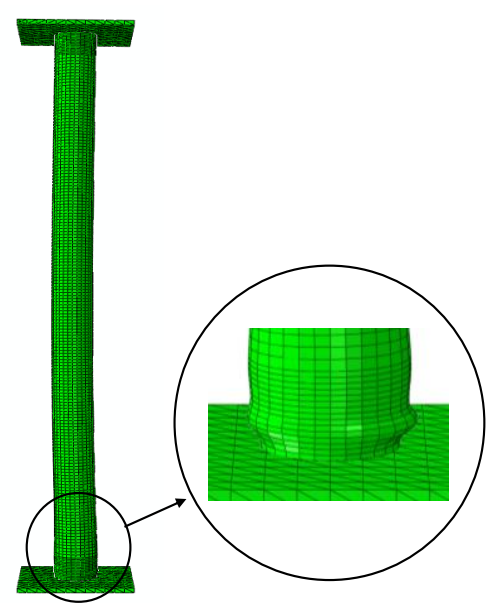

(a)

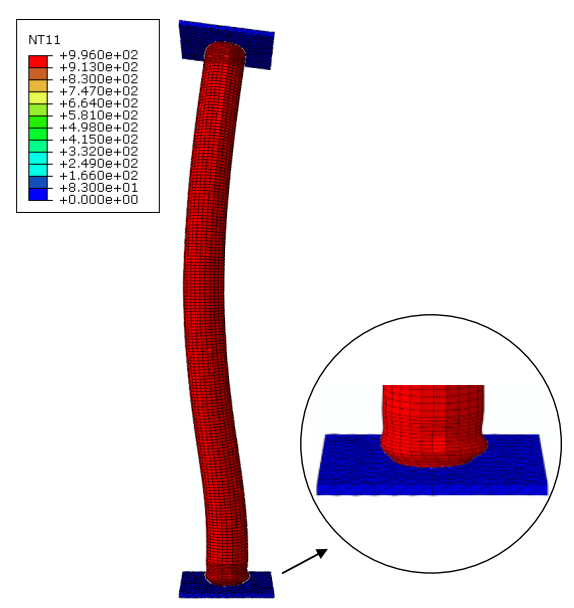

(b)

Fig. 6. The final deformed shape of column C-1D after subjected to the (a) lateral cyclic loading, and (b) ensuing fire (color counter shows the temperature distribution within the column) 
The axial displacement history of modelled column against fire, both after and before seismic damage is illustrated in Fig. 7.

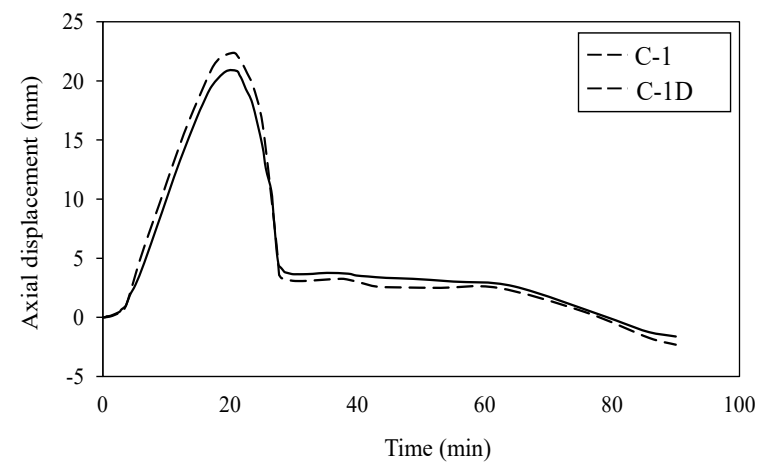

Fig. 7. Comparison of axial displacement history between columns C-1D and C-1 at fire

Even if the residual deformations at the bottom of column C-1D due to cyclic loading were considered as the initial condition, the axial displacement of column C-1D was very close to the behavior of an intact specimen (Fig. 7). This similar response could be because of the difference in the location of cyclic and thermally induced local bucklings, which were at the bottom and top region, respectively. This may avoid the combination of seismic-fire damage in the model. So, to come up this, another seismic damage scenario as 'top' damage was considered and analyzed afterwards.

\subsection{Top seismic damage scenario}

Figure 8 compares the final deformed shape of an intact column (C-1) with that of the specimen damaged due to earthquake loading close to the top ending, after subjected to the ensuing fire.

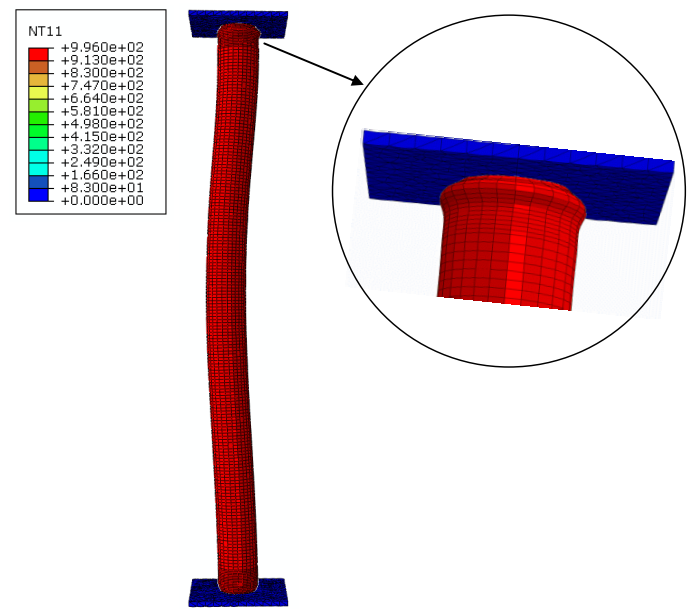

(a)

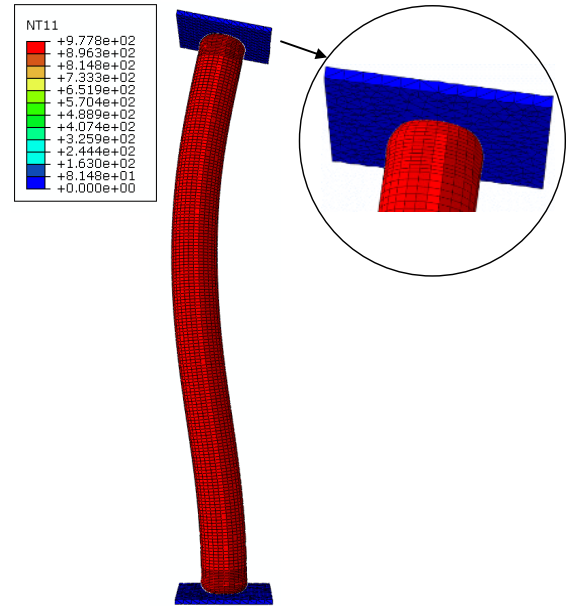

(b)

Fig. 8. The final deformed shape of column (a) damaged seismically at top and (b) C1, after the exposure to fire (color counter shows the temperature distribution within the columns)

Figure 9 illustrates the axial displacement history of the column in the condition that the seismic damage was located at the top ending.

Results reveal that the CFT column, which was damaged seismically at the top ending, failed due to the out of plane global buckling, which was similar to the behavior of column with the bottom ending damage (C-1D) as well as that of an intact one at fire. Since the final failure of seismically damaged column occurred due to the global buckling, the fire resistance time in both seismic damage locations was similar to each other (Fig. 9).

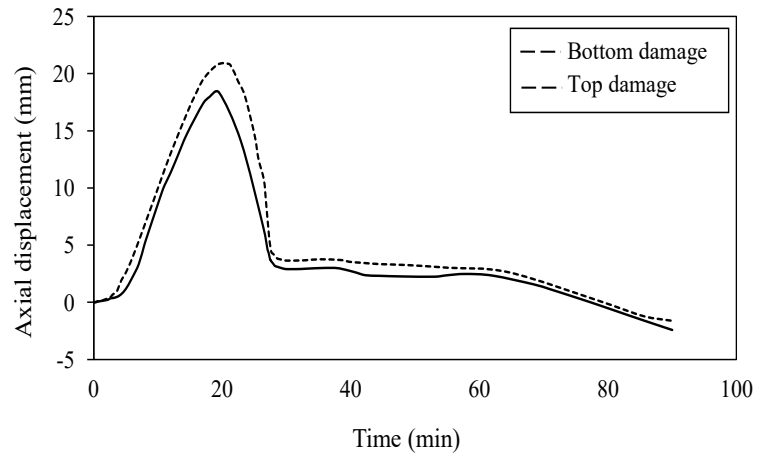

Fig. 9. Axial displacement history of CFT column with seismic damage at top and bottom ending after exposure to the fire

Given that both columns with the existing damage at the top and bottom end regions as well as the intact column failed due to the out of plane global buckling at fire, the middle span damage would basically influence the fire 
response of CFT columns. In this regard, the third damage scenario was considered, such that the maximum moment would be generated at the middle span of the column due to the lateral loading, follows by the development of damage at the middle length of the corresponding member.

\subsection{Middle length seismic damage scenario}

Figure 10 presents the final deformed state of column C-1 with the middle span seismic damage (labeled as C-1DM) after subjected to fire.

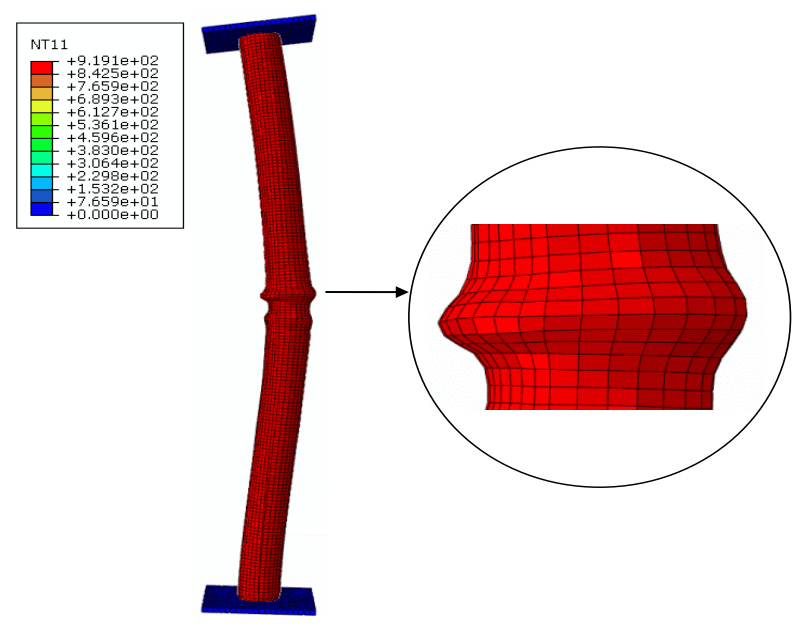

Fig. 10. The final deformed shape of the column with the middle length seismic damage (C-1DM) after fire (color counter shows the temperature distribution within the column)

As it was anticipated, the middle length damage made the column more susceptible to resist the fire. This concept can be better interpreted from the extension and contraction of column C-1DM due to fire loading, which is illustrated Fig. 11.

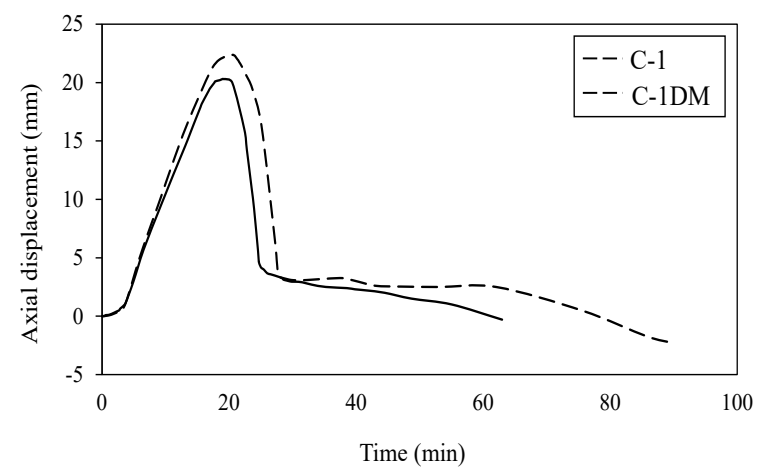

Fig. 11. Axial displacement versus time for column C-1DM and C-1 at fire
Figure 11 reveals that the global failure of column C-1DM occurred after 63 minutes of heating at fire while the intact column resisted the fire for 90 minutes. This could be in supporting the idea that the coincidence of seismic damage location to that of the onset of global buckling in column C-1DM, decreased the confinement effect provided by the steel tube to the in-filled concrete, resulting to a weaker fire response.

\section{Summary and conclusions}

In this study a three dimensional numerical model on predicting the fire response of seismically damaged concrete filled tube (CFT) columns was developed, using ABAQUS program. Three damage scenarios were considered in the column, namely middle length, bottom and top ending damages.

The results showed that the location of seismic damage at the top and bottom end regions has not remarkably influenced the fire resistance of columns. However, when the seismic damage was at the top of the column, the steel tube could not expand as high as when the existing damage was at the bottom ending. This was owing to the further transversal growth of existing seismic damage while subjected to the elevated temperatures, resulted to a lesser longitudinal expansion of tube.

The existence of seismic damage at the middle length of the column has mainly influenced the fire response of CFT column, which led to about 27 minutes shorter fire resistance time as compared to the cases that the damage was close to the end plates. This could be due to the coincidence of damage location to that of the onset of global buckling in the column with mid-span damage.

In general, it is anticipated that when the CFT column is damaged locally due to seismic loading while still maintains its stability, it behaves in a ductile manner under postearthquake fires, thanks to the composite action between the steel tube and the concrete core.

\section{Acknowledgements}

The research presented in this paper is based on the work funded by Alexander von Humboldt $(\mathrm{AvH})$ foundation under a postdoctoral award scheme. This support is greatly appreciated. 


\section{References}

[1] Hajjar JF. Concrete-filled steel tube columns under earthquake loads. Progress in Structural Engineering and Materials 2000; 2(1):72-81.

[2] Elremaily A, Azizinamini A. Behavior and strength of circular concrete-filled tube columns. Journal of Constructional Steel Research 2002; 58:1567-15.

[3] Han LH, Yang YF. Cyclic performance of concrete-filled steel CHS columns under flexural loading. Journal of Constructional Steel Research 2005; 61(4): 423-52.

[4] Lie TT, Chabot M. Experimental studies on the fire resistance of hollow steel columns filled with plain concrete. Internal Report No. 611. Ottawa (Canada): Institute for Research in Construction, National Research Council of Canada. NRCC.1992.

[5] Han LH, Zhao XL, Yang YF, Feng JB. Experimental study and calculation of fire resistance of concrete-filled hollow steel columns. Journal of Structural Engineering, ASCE 2003; 129(3): 346-56.

[6] Hong S, Varma AH. Analytical modeling of the standard fire behavior of loaded CFT columns. Journal of Constructional Steel Research 2009; 65:54-69.

[7] Moliner V, Espinos A, Romero ML, Hospitaler A. Fire behavior of eccentrically loaded slender high strength concrete-filled tubular columns. Journal of Constructional Steel Research 2013; 83(4):137-146.

[8] Ding J, Wang YC. Realistic modelling of thermal and structural behaviour of unprotected concrete filled tubular columns in fire. Journal of Constructional Steel Research 2008; 64:1086-102.

[9] Espinos A, Romero ML, Hospitaler A. Advanced model for predicting the fire response of concrete filled tubular columns. Journal of Constructional Steel Research 2010; 66:103046.

[10]Renaud C, Aribert JM, Zhao B. Advanced numerical model for the fire behavior of composite columns with hollow steel section. Steel and Composite Structures 2003; 3(2):7595.
[11]Zha XX. FE analysis of fire resistance of concrete filled CHS columns. Journal of Constructional Steel Research 2003; 59:769-79.

[12] Hu HAT, Huang CS, Chen ZL. Finite element analysis of CFT columns subjected to an axial compressive force and bending moment in combination. Journal of Constructional Steel Research 2005; 61:1692-1712.

[13] Goto Y, Kumar GP, Kawanishi N. Nonlinear finite-element analysis for hysteretic behavior of thin-walled circular steel columns with in-filled concrete. Journal of Structural Engineering, ASCE 2010; 136(11):1413-22.

[14]Chang X, Wei YY, Yun YC. Analysis of steelreinforced concrete-filled steel tubular (SRCFST) columns under cyclic loading. Construction and Building Materials 2012; 28:88-95.

[15] Scawthorn CR. Fire following earthquake. USGS Open File Report 2008; 200-1150.

[16] Scawthorn C, Eidinger JM, Schiff AJ. Fire following earthquake. Technical Council on Lifeline Earthquake Engineering Monograph, No. 26. American Society of Civil Engineers. 2005.

[17]ABAQUS. ABAQUS/standard version 2016 user's manual: volumes I-III. Pawtucket, Rhode Island: Hibbit, Karlsson \& Sorenson, Inc.; 2016.

[18]ATC-24. Guidelines for cyclic seismic testing of components of steel structures, Redwood City (CA): Applied Technology Council; 1992.

[19] Talebi E, Korzen M, Hothan S. The performance of concrete filled steel tube columns under post-earthquake fires. Journal of Constructional Steel Research 2017 (Submitted).

[20]EC4. EN 1994-1-1, Eurocode 4: Design of composite steel and concrete structures-Part 1-1: General rules and rules for buildings. Brussels (Belgium): European Committee for Standardization; 2004.

[21] ISO (International Standards Organization). ISO 834: fire resistance tests, elements of building construction. Switzerland: International Standards $\quad$ Organization; 1980. 